\title{
Empathy, Compassionate Altruism and Psychological Well-Being in Contemplative Practitioners across Five Traditions
}

\author{
Lynn E. O'Connor ${ }^{*}$, Rachna K. Rangan1, Jack W. Berry², David J. Stiver ${ }^{3}$, Rick Hanson', \\ Win Ark' ${ }^{1}$, Toni $\mathrm{Li}^{1}$ \\ ${ }^{1}$ The Wright Institute, Berkeley, USA \\ ${ }^{2}$ Department of Psychology, Samford University, Birmingham, USA \\ ${ }^{3}$ Graduate Theological Union, Berkeley, USA \\ ${ }^{4}$ Wellspring Institute for Neuroscience and Contemplative Wisdom, San Rafael, USA \\ Email: ${ }^{*}$ loconnor@wi.edu
}

Received 23 March 2015; accepted 23 June 2015; published 26 June 2015

Copyright (C) 2015 by authors and Scientific Research Publishing Inc.

This work is licensed under the Creative Commons Attribution International License (CC BY).

http://creativecommons.org/licenses/by/4.0/

c) (i) Open Access

\begin{abstract}
In an online anonymous study we compared 2409 contemplative practitioners to 450 non-meditators on measures of psychological functioning. The meditators followed five traditions: Tibetan and Theravada Buddhism, Centering Prayer, Yoga and Mindfulness. Meditators were lower in depression, neuroticism, empathic distress, and types of empathy-based guilt, and higher in empathy (cognitive and emotional), agreeableness, conscientiousness, openness, resilience, and compassionate altruism towards strangers. Comparing traditions found Tibetans and Centering Prayer higher in altruism towards strangers and Centering Prayer lower in neuroticism. In all traditions, intensity and duration of practice predicted positive outcomes. Meditators whose goal was benefit to others, compared to those whose goal was benefit to the self, were lower in depression, empathic distress, and neuroticism, and higher in cognitive empathy, resilience, and altruism towards strangers. Religion-based practitioners were lower in guilt, empathic distress, depression and neuroticism, and higher in conscientiousness, resilience, and altruism towards others compared secular meditators.
\end{abstract}

\section{Keywords}

Compassion, Depression, Resilience, Meditation, Religion

\footnotetext{
${ }^{*}$ Corresponding author.

How to cite this paper: O'Connor, L. E., Rangan, R. K., Berry, J. W., Stiver, D. J., Hanson, R., Ark, W., \& Li, T. (2015). Empathy, Compassionate Altruism and Psychological Well-Being in Contemplative Practitioners across Five Traditions. Psychology, 6, 989-1000. http://dx.doi.org/10.4236/psych.2015.68096
} 


\section{Introduction}

Meditation, or "contemplative practice" often referred to as mindfulness, is rapidly spreading in Western cultures, as many adopt it as a method of stress reduction. Likewise, clinically-focused professionals are using meditation to treat a range of diagnosable mental disorders as well as less serious problems in living. Derived from Eastern religious traditions, contemplative practices captured the attention and imagination of the 1960's "drop out" generation of Westerners seeking respite from secular Western culture. Not far behind were a handful of clinical professionals, some of whom were part of the rebellious group who first experimented with meditation. Noting the personal effectiveness of meditation, they began conducting empirical studies, developing what has come to be called contemplative science.

As practitioners and scientists began to investigate ancient religion-based systems, researchers in medicine, psychiatry and psychology initiated studies of the effects of meditation on human biological and psychological systems. Behanan (1937), a pioneer in contemplative science, discovered that the yoga practice of pranayama breathing significantly increases oxygen consumption. Wenger, Bagchi, and Anand (1961), studying Indian Yogis, found physiological changes in various bodily functions under autonomic control such as breathing, heart rate, temperature, and blood pressure during meditation practice. In the 1980s Yogi Bhajan (1997) migrated to the West where he began openly teaching Kundalini Yoga, breaking the historical tradition of secrecy, while encouraging research on its physiological and psychological benefits. Benson and colleagues (Benson, Beary, \& Carol, 1974; Wallace \& Benson, 1972; Wallace, Benson, \& Wilson, 1971) initiated studies of the physiology and psychiatric effects of a secularized version of Transcendental Meditation (TM), an Indian-Hindu practice already popularized in the West by the Indian Guru Maharishi, calling it "the relaxation response". A decade later Benson (1982) turned his attention to Tum-mo, a practice used by Tibetan yogis to raise body temperature, helpful in the freezing Himalaya. Further, in early contemplative neuroscience, Davidson, Coleman, \& Schwartz (1976) began investigating the effects of meditation on attention and affect.

In the past decade these pioneers have been joined by multiple teams of scientists in studying the beneficial effects of contemplative practices on biological and psychological systems, using measurable outcomes, including reduced stress, positive physiological and neurological changes, measured using fMRI and EEGs, changes in personality, and in vulnerability to mental disorders (Lutz, Brefczynski-Lewis, Johnstone, \& Davison, 2008; Lutz, Slagter, Dunne, \& Davidson, 2008). Contemplative practices such as mindfulness-based meditation, the relaxation response, and compassion meditation have also demonstrated a significant association with improved immune function (Benson, Beary, \& Carol, 1974; Davidson et al., 2003), reduced blood pressure and cortisol levels (Carlson et al., 2007) and increased telomerase activity (Jacobs et al., 2011). Meditation techniques have also been found to reduce symptoms associated with psychiatric disorders, such as anxiety (Hofmann et al., 2010; Shannahoff-Khalsa, 2004), depression (Hofmann et al., 2010; Teasdale et al., 2000), substance abuse (Benson, 1974; Bowen et al., 2006) chronic pain (Grossman et al., 2007), obsessive-compulsive and OC spectrum disorders (Shannahoff-Khalsa, 2003).

Studies conducted in Davidson's lab, using fMRI and EEGs, found that highly experienced Tibetan "adepts”, exhibit enhanced emotion regulation, a higher level of positive emotions, physical and psychological well-being, and a tendency to demonstrate high levels of interconnection between neural pathways associated with heightened analytical abilities, along with protection from vulnerability to stress and mental disorders (Lutz et al., 2004). The effectiveness of meditation in treating and/or preventing mental disorders has been found to occur as a function of practice in both naturalistic and laboratory settings and is being reported by front-line clinicians as well as by contemplative scientists. The association between meditation training and increases in altruistic behavior has also been demonstrated (O’Connor, Berry, Stiver, \& Rangan, 2012; Weng et al., 2013).

Though rooted in Eastern religious traditions, contemplative practices such as mindfulness and Mindfulness Based Stress Reduction (Kabat-Zinn, 2011) have been secularized to meet the needs of westerners. The positive effects reported by experimenters, some of whom themselves developed the treatment, may have been overstated, with the occasional negative effects ignored, and the difficulties inherent in outcome research fail to be addressed (Britton \& Heuman, 2014). A recent meta-analysis suggests that mindfulness practices compared to active placebo found only modest improvements in anxiety and depression (Goyal et al., 2014).

Religious and non-religious traditions may represent a variety of goals: To increase attention and concentration, reduce anxiety and depression, increase personal happiness and well-being, deepen understanding and philosophical insight, cultivate awareness of the interconnectedness of all life, develop greater compassion towards 
self and others, and finally, in the religious traditions, to benefit all living beings and to achieve the state of enlightenment. Although contemplative traditions may differ in techniques, in specific spiritual beliefs and in overall world-view and the goals of practice, they all share a common belief in the importance of compassion extended towards oneself and others, and selfless acts of kindness, including kindness to strangers.

Quantitative and qualitative studies demonstrating that Tibetan Buddhists, migrating to India, appear to exhibit protective factors in terms of reactions to stress, vulnerability to PTSD, and depression, despite trauma they experienced in Tibet and during their escape over the Himalaya (Keller et al., 2006; Sachs, Rosenfeld, Lhewa, Rasmussen, \& Keller, 2008). To investigate further, we conducted an anonymous online study, comparing 98 Tibetan Buddhist practitioners to a sample of 440 non-practitioners on psychological and social measures, including: proneness to acts of altruism towards family, friends and strangers, cognitive and emotional empathy, empathy-based guilt, depression and anxiety, as well as other personality factors. We also examined the effect of consistency and intensity of contemplative practices, on indices that have implications for social and psychological well-being (O’Connor et al., 2012). We found the Tibetan Buddhists demonstrated significantly lower levels of empathy-based pathogenic guilt (Omnipotent Responsibility Guilt), lower levels of pathogenic empathy (Empathic Distress), Depression, and Neuroticism, and perhaps most important, significantly higher levels of Compassionate Altruism towards Strangers. Within the group of Tibetan Buddhists, we found significant positive correlations between these variables and intensity of practice. The more one practiced, the better the outcomes (O'Connor et al., 2012). This matched the data found in Davidson's lab, where lifetime hours of meditation correlated with positive outcomes (Lutz et al., 2009).

While numerous studies have examined the benefits of contemplative practice, none appear to have compared specific contemplative practices to one another on psychological outcomes. Expanding our earlier study of Tibetan Buddhists, we added a larger population of practitioners from four other common practices, in order to compare them to one another, and to a non-practicing sample. Contemplative groups included: Tibetan, Theravada, Christian (Centering Prayer), Mindfulness (secular), and Yoga (primarily secular). We aimed to determine if these traditions would differ from one another in their ability to enhance positive psychosocial outcomes. We asked if practitioners of contemporary secular mindfulness meditation practices benefit from the same kind of emotion regulation, in terms of controlling or inhibiting empathy-based pathogenic guilt that we had found in the Tibetan Buddhist sample. We also wanted to know if contemplative practices embedded in a religious belief system were more likely to have a positive impact when compared to secular (non-religious) contemplative practices. We hypothesized that all groups of practitioners, when compared to non-practitioners, would exhibit significantly better outcomes. Following on Lutz et al. $(2004,2008)$ findings in neuroscience demonstrating that intensity—or hours over the lifetime-predicted better outcomes, we also hypothesized that intensity of meditative practice, across traditions, would predict positive outcomes. Finally, we predicted that practices embedded in a religion, and those focused on the well-being of others would demonstrate significantly greater benefits when compared to practices focused primarily on the self, or personal well-being.

\section{Method}

\subsection{Participants and Procedures}

To compare various contemplative practices we conducted an anonymous online survey that included 2409 practitioners and 450 non-practitioners. The practitioner survey was announced on Rick Hanson's blog (www.rickhanson.net), Craigslist, and on a variety of Tibetan Buddhist listservs connected to the Foundation for the Preservation of the Mahayana Tradition (FPMT) in the United States and in the newsletter of the International Organization of Tibetan Buddhist Monastics. Participants who were interested followed the link provided directing them to the study. There, they found an introductory page covering the specifics of informed consent, emphasizing the voluntary and confidential (anonymous) nature of the study, the right to withdraw without penalty, the age requirement for participation, approximate time to complete the survey, and contact information for the investigator and the IRB. After reading through this material, those who wanted to go on and participate were instructed to click on the link, indicating their consent to be a part of the study.

The Contemplative Practitioner sample $(N=2409$; 84.8\% female; mean age 52.5 years; range 18-87) represent the following practices: Tibetan $(n=156)$, Theravada $(n=136)$, Centering Prayer $(n=108)$ and Mindfulness (including Mindfulness-based Stress Reduction and Other Mindfulness) $(n=1071)$, Soto Zen, $(n=$ 
36), Pure Land Buddhism $(n=9)$, Yoga $(n=309)$, and a variety of other and mixed practices $(n=250)$. Most participants were European American (78.8\%); other ethnicities included Asian/Indian/Pacific Islanders (2.2\%), Latin American (2.0\%), African American (1.2\%), and small sample of self-identified as Other or Mixed. Current religious identifications were as follows: Buddhist (including Tibetan and Theraveda) (23.2\%), Christian (13.5\%), Jewish (3.2\%), Hindu (0.8\%), none (35.8\%), and other or non-response (28.2\%). The sample was highly educated, with $14.2 \%$ with a doctoral degree, $39.5 \%$ with a master's degree, $19.3 \%$ with a bachelor's degree, and $24.2 \%$ with some college education.

The general population sample ( $N=450$; $85.4 \%$ female; mean age 30.4 years; range 18 - 72) completed an online survey that included most of the psychological outcome variables as the contemplative group. Most of the samples were European Americans (60\%) or Asian-Americans (19\%). Religious identifications were 53.8\% Christian, 8.4\% Jewish, 2.7\% Buddhist, 1.3\% Muslim, 17.1\% none, and 16\% other or non-response. The sample was well-educated, with $3 \%$ having a doctoral degree, $13.8 \%$ a master's degree, $33.1 \%$ a bachelor's degree, and $39.8 \%$ with some college education.

\subsection{Instruments}

The Interpersonal Guilt Questionnaire-67 (IGQ-67; O’Connor, Berry, Weiss, Bush, \& Sampson, 1997) is a 67-item measure, using Likert-type scales, to assess empathy-based guilt. Three subscales were used in this study: Survivor Guilt is characterized by the belief that being successful or happy will make others feel inadequate simply by comparison (e.g., "It makes me very uncomfortable to receive better treatment than the people I am with"). Separation Guilt is characterized by the belief that if a person separates, leads his or her own life, or differs from loved ones in some way, he or she will cause loved ones to suffer (e.g. "I am reluctant to express an opinion that is different from the opinions held by my family or friends"). Omnipotent Responsibility Guilt is characterized by the belief that one is responsible for the happiness and well-being of others (e.g. "I often find myself doing what someone else wants me to do, rather than doing what I would most enjoy"). The construct validity of the IGQ-67 subscales has been supported in numerous studies (O'Connor, Berry, Lewis, \& Stiver, 2011; O’Connor, Berry, Weiss, \& Gilbert, 2002).

The Compassionate Altruism Scale (CAS; Berry, O’Connor, Rangan, \& Stiver, 2012) is a 45-item instrument, derived from a well-known and widely used measure of social support (Vaux, Riedel, \& Stewart, 1987). Instead of measuring how much social support a person received, the CAS measures how much support someone tends to extend to others. Respondents indicate how frequently they perform acts of altruism for family members, friends, and strangers in a variety of social situations. Items from this questionnaire include how often the participant helped others in terms of providing financial, social and emotional assistance. Examples of items are "Gave money for an indefinite amount of time" and "Helped them think about a problem".

The Interpersonal Reactivity Index (IRI; Davis, 1983): The IRI is a 28-item self-report instrument measuring distinct categories of empathy. Perspective taking is the ability to identify with, or understand cognitively the situation experienced by another person. Empathic Concern is the degree of concern a person tends to feel on witnessing difficult or unpleasant experiences occurring to another person. Personal Distress is the degree of distress a person is likely to feel, upon witnessing difficulties experienced by another person.

The Center for Epidemiologic Studies Depression Scale (CESD; Radloff, 1977) is a widely-used 20-item selfreport instrument, with responses on a Likert scale ranging from 0 to 3 , and total scores ranging from 0 to 60 . The cut off score for depression is equal to or greater than 16, which indicates at least a mild depression, though many clinicians mark a mild depression staring well below 16.

The Big Five Inventory (BFI; John, Donahue, \& Kentle, 1992) is a 44-item self-report inventory for assessing five personality traits: openness to experience, conscientiousness, extraversion, agreeableness, and neuroticism. In addition to using the subscales of the BFI, we added the subscales (after reverse scoring neuroticism) to obtain a measure of the General Factor of Personality (GPF). The GFP is often interpreted as a global measures of resilience and effective social functioning (Rushton \& Irwing, 2011; van der Linden, teNijenhuis, \& Bakker, 2010).

In addition to the standardized instruments, the participants also responded to a quantitative survey that included questions about their meditation practices. Responses were used to determine practice variables such as specific tradition, frequency of meditation, duration of sessions, and how long the participant has been meditating. Two derived, ordinal measures were calculated from these responses: intensity of meditation (frequency $\times$ duration of sessions) and total strength of meditation (intensity $\times$ how long the participant has been meditating). The questions about meditation practice also included an item asking "What is the main goal of your meditation?" 
The response options were "to relax", "improve my health", “make me more positive in general”, "get out of samsara or cyclic existence", "become enlightened” or "benefit all sentient beings".

\section{Results}

\subsection{Contemplative Practitioners versus General Population}

We first compared the full sample of contemplative practitioners to the general population sample on traits related to empathy, guilt, depression (CESD), and the Big Five personality factors. Table 1 shows independentsamples t-tests for these comparisons. There were significant group differences for all variables except the personality factor of extraversion and altruism to family. The contemplatives were significantly higher in empathic concern, perspective-taking, empathy-based survivor guilt (guilt over being better off than others), altruism towards strangers, agreeableness, conscientiousness, openness to experience, and the general factor of personality. The contemplatives were significantly lower on depression, empathic distress, altruism to friends, neuroticism and omnipotent responsibility guilt. These results suggest better psychosocial functioning and positive personality traits in the contemplative practitioner group compared to a non-practicing community sample.

\subsection{Practice Characteristics within the Contemplative Practitioner Sample}

In the full contemplative practitioner sample, we examined the rank correlation between meditation practice variables and psychosocial outcomes (depression, guilt, empathy, altruism, and personality factors). The practice variables were (1) practice intensity (product of frequency of mediation and duration of sessions); (2) How long meditating (from "Do not meditate" to "Over five years"); and (3) Strength of Practice (product of intensity of

Table 1. Contemplatives vs. non-contemplatives on psychological outcomes.

\begin{tabular}{|c|c|c|c|}
\hline & Contemplatives & Non-Contemplatives & \\
\hline & $\mathrm{M}(\mathrm{SD})$ & $\mathrm{M}(\mathrm{SD})$ & $t$ \\
\hline Survivor Guilt & $70.0(9.91)$ & $68.3(11.1)$ & $3.11^{* *}$ \\
\hline Separation Guilt & 34.8 (7.67) & $37.6(8.78)$ & $-6.33^{* * *}$ \\
\hline Omnipotence Guilt & $44.5(7.92)$ & $47.5(8.02)$ & $-7.52^{* * *}$ \\
\hline Perspective Taking & $26.2(4.58)$ & $25.3(4.89)$ & $3.47^{* *}$ \\
\hline Empathic Concern & $28.6(3.87)$ & $27.8(4.27)$ & $3.69^{* * *}$ \\
\hline Empathic Distress & $15.6(4.96)$ & $17.3(5.32)$ & $-6.10^{* * *}$ \\
\hline Altruism-Family & $172.4(29.4)$ & $170.5(32.0)$ & 1.13 \\
\hline Altruism-Friends & $167.5(25.5)$ & $174.1(28.1)$ & $-4.58^{* * *}$ \\
\hline Altruism-Strangers & $100.8(30.5)$ & 91.7 (31.8) & $5.71^{* * *}$ \\
\hline CESD & $12.5(10.7)$ & $21.5(13.1)$ & $-6.64^{* * *}$ \\
\hline Extraversion & $25.8(6.72)$ & $25.6(7.11)$ & 0.71 \\
\hline Agreeableness & $36.0(5.09)$ & $33.4(5.60)$ & $9.06^{* * *}$ \\
\hline Conscientiousness & $34.5(6.00)$ & $31.3(6.52)$ & $10.05^{* * *}$ \\
\hline Neuroticism & $21.5(6.74)$ & $25.2(6.65)$ & $-10.62^{* * *}$ \\
\hline Openness & 40.8 (5.93) & $39.3(6.22)$ & $4.83^{* * *}$ \\
\hline GFP & $121.7(19.6)$ & 110.4 (19.6) & $10.99^{* * *}$ \\
\hline
\end{tabular}

Note: GPF = General factor of personality; For the CESD comparison, $d f=2443$; for other comparisons, $d f$ ranged from $2782-2850 .{ }^{* *} p<.01 ;{ }^{* * *} p$ $<.001$. 
meditation with how long meditating). The correlations are shown in Table 2. In general, more intense meditation practice, and meditation over a longer period of time, was associated with higher altruism (especially toward strangers), better psychological functioning, and positive personality traits.

We also looked at the relationship between the most important goal of the meditation practice, selected by respondents in a forced choice question, and psychological well-being. For our analyses, we classified the most important goal of mediation as either "self-focused" ("relax", "improve my health", "make me more positive in general", "get out of samsara or cyclic existence", or "become enlightened") or "other focused" ("benefit all sentient beings"). Independent-samples $t$-tests were used to compare practitioners with these two classes of goals on psychological outcomes (see Table 3). The results show that participants whose goals of meditation were other-focused were significantly higher in compassionate altruism towards strangers, empathy-perspective taking (the cognitive aspect to empathy), extraversion, agreeableness, conscientiousness, openness, and the general factor of personality; they were significantly lower on depression, emphatic distress, separation guilt, and the personality factor, neuroticism, that represents proneness to anxiety and negative emotions.

\subsection{Comparison of Religious and Secular-Based Contemplative Practices on Psychological Outcomes}

The previous analyses included all contemplative practitioners who completed the survey. We next examined subgroups of practitioners based on whether their practices were explicitly religious or nonreligious. Three of the contemplative practices are explicitly religious in nature: Tibetan (practice of Mahayana or Vajrayana Buddhism); Theravada Buddhism; and Centering Prayer (Catholic in origin, and practiced by various Christian traditions). We classified Mindfulness (either Mindfulness-based Stress Reduction or any other mindfulness practice) and Yoga as primarily secular. We conducted ANOVAs to compare the separate religious practice groups and the secular practice group to the general population group on the empathy, guilt, depression, and personality variables (see Table 4). Dunnett's $t$-tests were used for the post hoc comparisons. All practitioner groups were

Table 2. Correlations within the contemplative practitioner sample.

\begin{tabular}{|c|c|c|c|}
\hline & Intensity of Practice & How Long Meditating & Strength of Practice \\
\hline Survivor Guilt & $-.08^{* *}$ & $-.10^{* * *}$ & $-.09^{* * *}$ \\
\hline Separation Guilt & $-.13^{* * *}$ & $-.12^{* * *}$ & $-.13^{* * *}$ \\
\hline Omnipotence Guilt & $-.15^{* * *}$ & $-.16^{* * *}$ & $-.16^{* * *}$ \\
\hline Perspective-taking & $.05^{*}$ & $.13^{* * *}$ & $.11^{* * *}$ \\
\hline Empathic Concern & -.01 & $.06^{* *}$ & $.05^{*}$ \\
\hline Empathic Distress & $-.09^{* * *}$ & $-.12^{* * *}$ & $-.13^{* * *}$ \\
\hline Altruism-Family & .02 & $.05^{*}$ & .04 \\
\hline Altruism-Friends & .02 & $.05^{*}$ & $.05^{*}$ \\
\hline Altruism-Strangers & $.12^{* * *}$ & $.15^{* * *}$ & $.18^{* * *}$ \\
\hline CESD & $-.11^{* * *}$ & $-.18^{* * *}$ & $-.18^{* * *}$ \\
\hline Extraversion & .02 & $.08^{* *}$ & $.06^{*}$ \\
\hline Agreeableness & $.09^{* * *}$ & $.13^{* * *}$ & $.12^{* * *}$ \\
\hline Conscientiousness & $.09^{* * *}$ & $.09^{* * *}$ & $.12^{* * *}$ \\
\hline Neuroticism & $-.14^{* * *}$ & $-.17^{* * *}$ & $-.18^{* * *}$ \\
\hline Openness & $.12^{* * *}$ & $.17^{* * *}$ & $.17^{* * * *}$ \\
\hline GFP & $.14^{* * *}$ & $.20^{* * *}$ & $.20^{* * *}$ \\
\hline
\end{tabular}

Note: Spearman rank correlations. GPF = General factor of personality; Intensity of Practice $=$ frequency of practice $\times$ duration of sessions; Strength of Practice $=$ intensity of practice $\times$ how long meditating; Sample sizes for correlations range from $1828-2104 .^{*} p<0.05 ;{ }^{* *} p<.01 ;^{* * *} p<.001$ 
Table 3. Comparison of psychological outcomes based on self- vs. other-focused goals of contemplative practice.

\begin{tabular}{|c|c|c|c|}
\hline & Self-focused & Other-focused & \\
\hline & $\mathrm{M}(\mathrm{SD})$ & $\mathrm{M}(\mathrm{SD})$ & $t$ \\
\hline Survivor Guilt & $70.1(9.87)$ & $69.9(9.24)$ & 0.36 \\
\hline Separation Guilt & $34.9(7.47)$ & $33.2(6.89)$ & $3.95^{* *}$ \\
\hline Omnipotence Guilt & $44.5(7.66)$ & $42.9(7.60)$ & $3.32^{* *}$ \\
\hline Perspective Taking & $26.2(4.60)$ & $27.2(4.20)$ & $-3.98^{* *}$ \\
\hline Empathic Concern & 28.7 (3.73) & 29.3 (3.69) & -2.88 \\
\hline Empathic Distress & $15.7(4.96)$ & $14.4(44.5)$ & $4.53^{* *}$ \\
\hline Altruism-Family & $172.2(29.1)$ & $175.1(26.8)$ & -1.68 \\
\hline Altruism-Friends & $167.5(25.2)$ & $170.6(24.9)$ & -2.11 \\
\hline Altruism-Strangers & $100.3(29.8)$ & $112.4(31.3)$ & $-6.73^{* *}$ \\
\hline CESD & $12.6(10.7)$ & $10.2(8.97)$ & $4.25^{* *}$ \\
\hline Extraversion & $25.7(6.76)$ & $26.8(6.20)$ & $-2.86^{* *}$ \\
\hline Agreeableness & $35.9(5.02)$ & $37.4(4.75)$ & $-4.81^{* *}$ \\
\hline Conscientiousness & $34.4(5.93)$ & $35.3(5.63)$ & $-2.52^{*}$ \\
\hline Neuroticism & $21.6(6.65)$ & $19.4(6.47)$ & $5.55^{* *}$ \\
\hline Openness & $40.8(5.86)$ & $42.4(5.17)$ & $-4.82^{* *}$ \\
\hline GFP & $121.2(19.1)$ & $128.4(18.9)$ & $-6.35^{* *}$ \\
\hline
\end{tabular}

Note: GPF = General factor of personality; $d$ range from $1735-1753 .{ }^{*} p<.05 ;{ }^{* *} p<0.01$.

Table 4. Various contemplative practices and psychological outcomes.

\begin{tabular}{|c|c|c|c|c|c|c|c|}
\hline & Tibetan & Theraveda & Cent. Prayer & Mindfulness & Yoga & No Pract. & \\
\hline & $M$ & $M$ & $M$ & $M$ & $M$ & $M$ & $F$ \\
\hline Survivor Guilt & $70.8^{*}$ & 69.4 & 69.4 & $70.6^{* * *}$ & $70.4^{*}$ & 68.3 & $3.77^{* *}$ \\
\hline Separation Guilt & $34.0^{* * *}$ & $33.3^{* * *}$ & $34.5^{* *}$ & $34.7^{* * *}$ & 36.3 & 37.6 & $13.23^{* * *}$ \\
\hline Omnipotent Guilt & $43.7^{* * *}$ & $43.5^{* * *}$ & $43.8^{* * *}$ & $44.6^{* * *}$ & $45.6^{* *}$ & 47.5 & $13.19^{* * *}$ \\
\hline Perspective-taking & $26.6^{* *}$ & 26.3 & $26.6^{*}$ & $26.3^{* *}$ & 26.0 & 25.3 & $3.66^{* *}$ \\
\hline Empathic Concern & $29.0^{* *}$ & 28.6 & $29.1^{* *}$ & $28.7^{* * *}$ & $28.7^{*}$ & 27.8 & $4.81^{* * *}$ \\
\hline Empathic Distress & $14.8^{* * *}$ & $15.1^{* * *}$ & $15.3^{* *}$ & $15.6^{* * *}$ & $16.0^{* *}$ & 17.3 & $9.52^{* * *}$ \\
\hline Altruism-Family & 171.9 & 166.9 & 175.5 & 173.4 & 173.6 & 170.6 & 1.86 \\
\hline Altruism-Friends & 169.2 & $163.8^{* * *}$ & 170.1 & $167.7^{* * *}$ & 168.6 & 174.1 & $5.07^{* * *}$ \\
\hline Altruism-Strangers & $110.4^{* * *}$ & $100.5^{*}$ & $106.3^{* * *}$ & $100.9^{* * *}$ & 96.10 & 91.8 & $11.87^{* * *}$ \\
\hline CESD & $12.1^{* * *}$ & $10.2^{* * *}$ & $10.6^{* * *}$ & $12.9^{* * *}$ & $12.4^{* * *}$ & 21.5 & $15.34^{* * *}$ \\
\hline Extraversion & 26.4 & 25.2 & 26.9 & 25.6 & 26.3 & 25.6 & 1.66 \\
\hline Agreeableness & $36.0^{* * *}$ & $36.2^{* * *}$ & $37.5^{* * *}$ & $36.1^{* * *}$ & $36.0^{* * *}$ & 33.4 & $22.14^{* * *}$ \\
\hline Conscientiousness & $35.2^{* * *}$ & $34.9^{* * *}$ & $35.6^{* * *}$ & $34.2^{* * *}$ & $34.9^{* * *}$ & 31.3 & $21.13^{* * *}$ \\
\hline Neuroticism & $20.5^{* * *}$ & $20.5^{* * *}$ & $19.5^{* * *}$ & $21.9^{* * *}$ & $21.6^{* * *}$ & 25.3 & $26.39^{* * *}$ \\
\hline Openness & $41.7^{* * *}$ & 40.1 & $40.8^{*}$ & $40.8^{* * *}$ & $41.0^{* *}$ & 39.2 & $6.30^{* * *}$ \\
\hline GFP & $124.8^{* * * *}$ & $122.0^{* * *}$ & $127.2^{* * *}$ & $120.7^{* * *}$ & $122.6^{* * *}$ & 110.3 & $27.82^{* * *}$ \\
\hline
\end{tabular}

Note: GFP $=$ General factor of personality. For $F$ tests, total $d f$ for the CESD comparison was 1552; all other total $d f$ range from 1893 - 1918. Asterisks after means indicate a significant difference from the non-practitioner comparison group based on Dunnett's $t$-test. ${ }^{* *} p<.05 ;{ }^{* *} p<0.01 ;{ }^{* * * *} p<0.001$. 
significantly lower than the general population group on depression, neuroticism, omnipotence guilt, and empathic distress; all groups with the exception of Yoga were also lower on separation guilt. All practitioner groups with the exception of Yoga were significantly higher on altruism to strangers. All five groups were significantly higher on conscientiousness, agreeableness, and the general factor of personality representing emotional resilience. All practitioner groups except for the Theraveda group and the Yoga group were significantly higher than the general population in perspective-taking and empathic concern. All groups with the exception of Theravada were significantly higher in openness to experience. The Tibetan, Mindfulness and Yoga groups were significantly higher in survivor guilt compared to the general population group. Interestingly, the Theravada and mindfulness groups were significantly lower in altruism to friends than the comparison group (despite both being higher in altruism to strangers).

Finally, we combined the three religious practice groups and compared them to the secular practice groups (mindfulness and Yoga) on psycho-social outcome variables using independent-samples $t$-tests (see Table 5). We found the religiously based practitioners were significantly higher on altruism towards strangers, conscientiousness, and resilience compared to the secular groups, and significantly lower on depression, omnipotence guilt, empathic distress, and neuroticism, again compared to secular practitioners. There were no significant differences between the religious and secular contemplatives practitioners on altruism towards family and friends.

We also compared the religious and secular practitioners on the primary goal of meditation (self-focused versus other-focused). A significantly higher percentage of religiously based practitioners (38.89\%) endorsed otherfocused goals compared to the secular practitioners $(14.45 \%), \chi^{2}(1)=98.51, p<.001$. For the separate practitioner groups, other-focused goals were endorsed by 58.39\% Tibetan, $26.56 \%$ Theraveda, $22.89 \%$ Centering Prayer, 14.8\% Mindfulness (secular) and 13.06\% Yoga practitioners.

\section{Discussion}

This study supports the general scientific and clinical findings on contemplative practices: People engaged in contemplative practices appear less vulnerable to depression, anxiety, empathic distress, and maladaptive guilt,

Table 5. Comparison of religious and secular practice groups.

\begin{tabular}{cccc}
\hline & Secular Practice & Religious Practice & $\underline{t}$ \\
\hline Survivor Guilt & M (SD) & M (SD) & 1.15 \\
Separation Guilt & $70.6(9.99)$ & $69.9(8.98)$ & 1.86 \\
Omnipotence Guilt & $34.7(7.66)$ & $33.9(6.82)$ & $2.15^{*}$ \\
Perspective-taking & $44.6(7.76$ & $43.6(7.51)$ & -0.96 \\
Empathic Concern & $26.3(4.49)$ & $26.5(4.31)$ & -0.62 \\
Empathic Distress & $28.7(3.78)$ & $28.9(3.54)$ & $1.98^{*}$ \\
Altruism-Family & $15.6(5.04)$ & $15.1(4.82)$ & 1.24 \\
Altruism-Friends & $173.4(29.3)$ & $171.3(29.4)$ & 0.03 \\
Altruism-Strangers & $167.8(25.8)$ & $167.7(24.7)$ & $-2.77^{* *}$ \\
CESD & $100.9(30.0)$ & $105.8(30.6)$ & $3.04^{* *}$ \\
Extraversion & $12.9(10.7)$ & $11.0(10.0)$ & -1.29 \\
Agreeableness & $25.6(6.83)$ & $26.1(6.42)$ & -1.35 \\
Conscientiousness & $36.1(4.93)$ & $36.5(4.85)$ & $-2.90^{* *}$ \\
Neuroticism & $34.2(6.04)$ & $35.2(5.93)$ & $4.48^{* *}$ \\
Openness & $21.9(6.91)$ & $20.2(6.36)$ & -0.47 \\
GFP & $40.8(5.78)$ & $40.9(5.61)$ & $-3.33^{* *}$ \\
\hline
\end{tabular}

Note: GFP = General factor of personality. The $d f$ ranged from $1760-1776 .{ }^{*} p<.05 ;{ }^{* *} p<0.001$. 
as well as more resilient in general. In addition, to varying degrees, they all, with the exception of practitioners of Yoga who-in this sample-were secular, seem more likely to engage in acts of altruism towards strangers. While they appear to differ from one another, sometimes significantly, in various psychosocial outcomes, we found contemplative practice beneficial. Perhaps most striking is the finding related to kindness to strangers; across groups, with one exception, altruism extended beyond the close family or small group, tribal unit or what is commonly thought of as the "in-group," was significantly higher when compared to non-practitioners. The exception here, Yoga, may indicate some difference in yoga practitioners compared to the others. We debated this: Yoga as practiced in India is usually connected to a religion, Hinduism, which focuses on the interconnections of all living beings, and this sample failed to include Hindu-based Yoga practitioners. Likewise, Kundalini Yoga, as practiced in the west, is embedded in religious beliefs; however, this sample failed to include Kundalini practitioners. Today, Yoga, as practiced in the west has a different connotation; it is seen as a form of physical fitness training like aerobics or Pilates, and therefore we were unsure as to whether to include it in our analysis. However, given its popularity, and the large sample we collected, we decided to include and let future studies tease out the differences comparing secular-based Yoga to Yoga based in a spiritual tradition.

All other practitioners were found higher in altruism to strangers. In recent years, the motivation for altruistic behavior towards the "in-group" is increasingly accepted and supported by evolutionary biologists (Wilson \& Wilson, 2007) and accepted as an important factor in human evolution. Hard-wired empathy and fundamental altruism and compassion form the bedrock of the motivation to act altruistically in response to witnessing others in distress. This is supported by multilevel selection theory, including evolution at the level of the group, or group selection in between group competition. Groups with more altruists outcompete groups with fewer altruistic individuals.

Many Buddhists believe in "Buddha nature" referring to our intrinsically altruistic non-conscious mind. This may be relevant to the significant differences in compassionate kindness to strangers between secular and Buddhist practitioners. However, we also found another religiously based tradition, Centering Prayer, (most often practiced by Catholics) whose practitioners endorsed "benefit to all sentient beings" as their goal of meditation, was also higher in kindness to strangers. The Dalai Lama has frequently said that acts of kindness promote happiness, as well as serve to change the ills of the world and by he is not limiting his observations to Buddhist practitioners. Perhaps all religiously motivated contemplative practitioners share an emphasis on basic kindness or concern for others rather than the self, and furthermore, perhaps this is embedded in our fundamentally altruistic nature. Kindness to family and friends or close in-group members may in part be explained by the theories of kin selection and/or reciprocal altruism, but kindness to strangers is only explained by evolution at the level of the group. In terms of personal well-being, including levels of depression and anxiety, we found that contemplative practitioners from each tradition, when compared to a non-practicing population, benefited from their practice.

But again, within the groups of contemplatives, those engaged in religiously based practices (with the exception of Tibetan), were overall happier, as measured by lower rates of depression, than those whose practice was secular. It is possible that losing their country and enduring over 50 years of brutal oppression in Tibet accounts for slightly higher rates of depression when compared to other religious groups.

Tibetan and Centering Prayer practitioners demonstrated better outcomes in general when compared to the Theravada and mindfulness traditions. They also demonstrated significantly higher compassionate altruism directed towards strangers. We hypothesize that this difference may be the result of specific conditioning. In the Tibetan group, practitioners begin and end each meditation session with a statement of "motivation"- they are practicing for the "benefit of all sentient beings" and not for self-benefit. In contrast, in the Theravada tradition, which is also a Buddhist or religious practice, the orientation of practice, is more often for one's own enlightenment according to this sample. This difference in conditioning may explain the significantly lower level of compassionate altruism extended to strangers when compared to the Tibetan and Centering Prayer practitioners.

It has been noted that Westerners in general tend to suffer from a propensity to "self-hate", to view themselves negatively, and to engage in negative "self-talk". A fundamental world-view may be explanatory here. Many Tibetan Buddhists believe in universal "Buddha nature" whereas in the more western perspectives, there is a subtle belief in basic "badness", or "original sin". In the Freudian-influenced culture of the West, it is commonly believed that we are "unconsciously" full of greed, and malevolent emotions and intensions, whereas in the East, perhaps as a reflection of collectivistic cultures, there may be a more fundamental belief in our altruistic nature. Future research will need to further examine factors such as specific beliefs held by practitioners of different traditions, particular life experiences common to a culture, along with specific meditative techniques and 
other methods inherent to each type of practice.

\section{Conclusion}

This study comparing five contemplative traditions supports the current popularity in western cultures of contemplative practices that help to increase psychological resilience. While recent meta-analytic studies are suggesting that the positive effects of meditation (and mindfulness) may not be quite as dramatic as presented in the popular press and that contemplative practice may not always be good for everyone in every situation, overall, as confirmed by the findings here, meditation is beneficial. The finding that practitioners of contemplative practices, with exception of secular Yoga, tend to be higher in kindness extended to strangers may have important implications. Living in our global environment, where nations, social institutions and whole societies are widely interconnected, the need to enhance compassion across national, cultural and economic borders is ever more obvious. In the current context of exponential growth of populations, shortages of basic necessities such as food and water, and the potential for environmental catastrophe, the need to find means for enhancing cooperation and extending compassionate altruism to others is imperative.

\section{Acknowledgements}

This research was funded by a grant from the Meehan Foundation made to the Emotion, Personality and Altruism Research Group (EPARG), Wright Institute. We thank members of Tse Chen Ling, San Francisco, California, The International Mahayana Institute, and the Tibetan Mongolian Buddhist Cultural Center in Bloomington, Indiana, and the Wellspring Institute for Neuroscience and Contemplative Wisdom, San Rafael California for their participation in this study. We thank Patrice Crisostomo, U. Denver, for her help in gathering the non-practitioners data.

\section{References}

Behanan, K. T. (1937). Yoga: A Scientific Evaluation. New York: Dover Publications.

Benson, H. (1974). Decreased Alcohol Intake Associated with the Practice of Meditation: A Retrospective Investigation. Annals of the New York Academy of Sciences, 233, 174-177. http://dx.doi.org/10.1111/j.1749-6632.1974.tb40298.x

Benson, H. (1982). Body Temperature Changes During the Practice of g Tum-mo Yoga. Nature, 295, 234-235. http://dx.doi.org/10.1038/295234a0

Benson, H., Beary, J. F., \& Carol, M. P. (1974). The Relaxation Response. Psychiatry, 37, 37-46.

Berry, J. W., O’Connor, L. E., Rangan, R., \& Stiver, D. J. (2012). Development and Evaluation of the Compassionate Altruism Scale. Poster presented at the conference Science of Compassion: Origins, Measures and Interventions, Telluride, Colorado.

Bhajan, Y. (1997). The Master's Touch: On Being a Sacred Teacher for the New Age. Espanola, NM: Kundalini Research Institute Publications.

Bowen, S., Witkiewitz, K., Dilworth, T. M., Chawla, N., Simpson, T. L., Ostafin, B. D. et al. (2006). Mindfulness Meditation and Substance Use in an Incarcerated Population. Psychology of Addictive Behaviors, 20, 343-347. http://dx.doi.org/10.1037/0893-164X.20.3.343

Carlson, L. E., Speca, M., Faris, P., \& Patel, K. D. (2007). One Year Pre-Post Intervention Follow-Up of Psychological, Immune, Endocrine and Blood Pressure Outcomes of Mindfulness-Based Stress Reduction (MBSR) in Breast and Prostate Cancer Outpatients. Brain, Behavior, and Immunity, 21, 1038-1049. http://dx.doi.org/10.1016/j.bbi.2007.04.002

Davidson, R. I, Coleman, D. I., \& Schwartz, G. E. (1976). Attentional and Affective Concomitants of Meditation: A CrossSectional Study. Journal of Abnormal Psychology, 85, 235-238. http://dx.doi.org/10.1037/0021-843X.85.2.235

Davidson, R. J., Kabat-Zinn, J., Schumacher, J., Rosenkranz, M., Muller, D., Santorelli, S. F. et al. (2003). Alterations in Brain and Immune Function Produced by Mindfulness Meditation. Psychosomomatic Medicine, 65, 564-570. http://dx.doi.org/10.1097/01.PSY.0000077505.67574.E3

Davis, M. H. (1983). Measuring Individual Differences in Empathy: Evidence for a Multidimensional Approach. Journal of Personality and Social Psychology, 44, 113-126. http://dx.doi.org/10.1037/0022-3514.44.1.113

Goyal, M., Singh, S., Sibinga, E. M., Gould, N. F., Rowland-Seymour, A., Sharama, R. et al. (2014). Meditation Programs for Psychological Stress and Well-Being: A Systematic Review and Meta-Analysis. Journal of Internal Medicine, 174, 357-368. http://dx.doi.org/10.1001/jamainternmed.2013.13018

Grossman, P., Tiefenthaler-Gilmer, U., Raysz, A., \& Kesper, U. (2007). Mindfulness Training as an Intervention for Fibromyalgia: Evidence of Postintervention and 3-Year Follow-Up Benefits in Well-Being. Psychotherapy and Psychosomatics, 


\section{6, 226-233. http://dx.doi.org/10.1159/000101501}

Hofmann, S. G., Sawyer, A. T., Witt, A. A., \& Oh, D. (2010). The Effect of Mindfulness-Based Therapy on Anxiety and Depression: A Meta-Analytic Review. Journal of Consulting and Clinical Psychology, 78, 169-183. http://dx.doi.org/10.1037/a0018555

Jacobs, T. L., Epel, E. S., Lin, J., Blackburn, E. H., Wolkowitz, O. M., Bridwell D. A. et al. (2011). Intensive Meditation Training, Immune Cell Telomerase Activity, and Psychological Mediators. Psychoneuroendocrinology, 36, 664-681. http://dx.doi.org/10.1016/j.psyneuen.2010.09.010

John, O. P., Donahue, E. M., \& Kentle, R. (1992). The Big-Five Inventory-Versions 4a and 54. Technical Report, Berkeley, CA: Institute of Personality and Social Research, University of California.

Kabat-Zinn, J. (2011). Some Reflections on the Origins of MBSR, Skillful Means, and the Trouble with Maps. Contemporary Buddhism, 12, 281-306. http://dx.doi.org/10.1080/14639947.2011.564844

Keller, A., Lhewa, D., Rosenfeld, B., Sachs, E., Aladjem, A., Cohen, I. et al. (2006). Traumatic Experiences and Psychological Distress in an Urban Refugee Population Seeking Treatment Services. Journal of Nervous and Mental Disease, 194, 188-194. http://dx.doi.org/10.1097/01.nmd.0000202494.75723.83

Lutz, A., Greischar, L. L., Rawlings, N. B., Ricard M., \& Davidson, R. J. (2004). Long-Term Meditators Self-Induce HighAmplitude Gamma Synchrony during Mental Practice. Proceedings of the National Academy of Sciences of the United States of America, 101, 16369-16373. http://dx.doi.org/10.1073/pnas.0407401101

Lutz, A., Brefczynski-Lewis, J. A., Johnstone, T., \& Davidson, R. J. (2008). Regulation of the Neural Circuitry of Emotion by Compassion Meditation: Effects of Meditative Expertise. PLOS ONE, 3, e1897. http://dx.doi.org/10.1371/journal.pone.0001897

Lutz, A., Slagter, H. A., Dunne, J., \& Davidson, R. J. (2008). Attention Regulation and Monitoring in Meditation. Trends in Cognitive Sciences, 12, 163-169. http://dx.doi.org/10.1016/j.tics.2008.01.005

Lutz, A., Slagter, H. A., Rawlings, N. B., Francis, A. D., Greischar, L. L., \& Davidson, R. J. (2009). Mental Training Enhances Attentional Stability: Neural and Behavioral Evidence. Journal of Neuroscience, 29, 13418-13427. http://dx.doi.org/10.1523/JNEUROSCI.1614-09.2009

O’Connor, L. E., Berry, J. W., Weiss, J., Bush, M., \& Sampson, H. (1997). Interpersonal Guilt: The Development of a New Measure. Journal of Clinical Psychology, 53, 73-89. http://dx.doi.org/10.1002/(SICI)1097-4679(199701)53:1<73::AID-JCLP10>3.0.CO;2-I

O’Connor, L. E., Berry, J. W., Lewis, T., \& Stiver, D. J. (2011). Empathy-Based Pathogenic Guilt, Pathological Altruism, and Psychopathology. In, B. Oakley, A. Knafo, G. Madhavan, \& D. S. Wilson (Eds.), Pathological Altruism (pp. 11-30). New York: Oxford University Press. http://dx.doi.org/10.1093/acprof:oso/9780199738571.003.0024

O’Connor, L. E., Berry, J. W., Weiss, J., \& Gilbert, P. (2002). Guilt, Fear, Submission, and Empathy in Depression. Journal of Affective Disorders, 71, 19-27. http://dx.doi.org/10.1016/S0165-0327(01)00408-6

O’Connor, L., Berry, J. W., Stiver, D., \& Rangan, R. (2012). Depression, Guilt, and Tibetan Buddhism. Psychology, 3, 805809. http://dx.doi.org/10.4236/psych.2012.329122

Radloff, L. S. (1977). The CES-D Scale: A Self-Report Depression Scale for Research in the General Population. Applied Psychological Measurement, 1, 385-401. http://dx.doi.org/10.1177/014662167700100306

Rushton, J. P., \& Irwing, P. (2011). The General Factor of Personality: Normal and Abnormal. In T. Chamorro-Premuzic, S. von Stumm, \& A. Furnham (Eds.), The Wiley-Blackwell Handbook of Individual Differences (pp. 132-161). London: Wiley-Blackwell.

Sachs, E., Rosenfeld, B., Lhewa, D., Rasmussen, A., \& Keller, A. (2008). Entering Exile: Trauma, Mental Health, and Coping among Tibetan Refugees arriving in Dharamsala, India. Journal of Traumatic Stress, 21, 199-208. http://dx.doi.org/10.1002/jts.20324

Shannahoff-Khalsa, D. S. (2003). Kundalini Yoga Meditation Techniques for the Treatment of Obsessive-Compulsive and OC Spectrum Disorders. Brief Treatment and Crisis Intervention, 3, 369-382. http://dx.doi.org/10.1093/brief-treatment/mhg027

Shannahoff-Khalsa, D. S. (2004). An Introduction to Kundalini Yoga Meditation Techniques that are Specific for the Treatment of Psychiatric Disorders. Journal of Alternative and Complementary Medicine, 10, 91-101. http://dx.doi.org/10.1089/107555304322849011

Teasdale, J. D., Segal, Z. V., Williams, J. M., Ridgeway, V. A., Soulsby, J. M., \& Lau, M. A. (2000). Prevention of Relapse/ Recurrence in Major Depression by Mindfulness-Based Cognitive Therapy. Journal of Consulting and Clinical Psychology, 8, 615-623. http://dx.doi.org/10.1037/0022-006X.68.4.615

van der Linden, D., teNijenhuis, J., \& Bakker, A. B. (2010). The General Factor of Personality: A Meta-Analysis of Big Five Intercorrelations and a Criterion-Related Validity Study. Journal of Research in Personality, 44, 315-327. http://dx.doi.org/10.1016/j.jrp.2010.03.003

Vaux, A., Riedel, S., \& Stewart, D. (1987). Modes of Social Support: The Social Support Behaviors (SS-B) Scale. American Journal of Community Psychology, 15, 209-237. http://dx.doi.org/10.1007/BF00919279 
Wallace, R. K., \& Benson, H. (1972). The Physiology of Meditation. Scientific American, 226, 84-90. http://dx.doi.org/10.1038/scientificamerican0272-84

Wallace, R. K., Benson, H., \& Wilson, A. F. (1971). A Wakeful Hypometabolic Physiologic State. The American Journal of Physiology, 221, 795-799.

Weng, H. Y., Fox, A. S., Shackman, A. J., Stodola, D. E., Caldwell, J. Z., Olson, M. C., Rogers, G. M., \& Davidson, R. J. (2013). Compassion Training Alters Altruism and Neural Responses to Suffering. Psychological Science, 24, 1171-1180. http://dx.doi.org/10.1177/0956797612469537

Wenger, M. A., Bagchi, B. K., \& Anand, B. K. (1961). Experiments in India on "Voluntary” Control of the Heart and Pulse. Circulation, 24, 1319-1325. http://dx.doi.org/10.1161/01.CIR.24.6.1319

Wilson, D. S., \& Wilson, E. O. (2007). Rethinking the Theoretical Foundation of Sociobiology. The Quarterly Review of Biology, 82, 327-348. http://dx.doi.org/10.1086/522809 